\title{
Functional and technological prerequisites for architectural and space-planning design of test centers for technical systems
}

\author{
Elena Suleimanova*1, and Dilyara Shireeva ${ }^{1[0000-0002-9709-2559]}$ \\ ${ }^{1}$ Kazan State University of Architecture and Engineering, 420043 Kazan, Russia
}

\begin{abstract}
Ensuring the reliability and safety of technical systems is a milestone in their development and mass production. Reliability testing of technical systems is performed in special laboratories and centers. Today, there is a great deal of experience in simulating operating conditions of technical systems in order to predict and increase their reliability. This paper discusses the identification of functional technological processes in the existing test centers for technical systems in order to develop their architectural and space-planning design. The test processes for technical systems have been classified. The analysis of the existing test centers for technical systems and the test procedures made it possible to identify the main infrastructure elements, as well as their equipment, which was necessary for laying down the principles of architectural and space-planning design of such centers as a separate design object.
\end{abstract}

Keywords. Test centers for technical systems, architectural and spaceplanning design, functional and technological prerequisites, reliability.

\section{Introduction}

Reliability tests are an important part of testing new machines. Testing has a special place in the whole «life cycle» of technical systems (aviation and engineering products, building structures, etc.), which includes designing, refining, mass production, operation, and repair. According to GOST (Russian Standard) 16504, test is an experimental determination of quantitative and/or qualitative characteristics of a test object as a result of it being exposed to mechanical and climatic factors during its operation. In many cases, testing accounts for most of costs of reliability. For example, labour intensity of test and control processes for aircrafts is $20-40 \%$ of total labour intensity of their production [1]. Long-term tests have a special place. Long-term exposure of materials to operational factors results in their degradation and therefore loss of performance. Experts estimate that more than $60 \%$ of equipment failures are related to the impact of climatic factors only [2, 3]. According to the data from [2], the annual worldwide losses due to ageing and failure of materials are estimated at 2.2 trillion US dollars and reach $3 \%$ of GDP for such countries as the USA, Great Britain, Germany. In 2011, the USA's direct losses were 468 billion US dollars. In 2010, the US Department of Defence alone spent 13.9 billion US dollars on minimization

*Corresponding author: elenasuleiman@rambler.ru 
and prevention of ageing and failure of materials. The total damage caused by operational factors is $3-10 \%$ of gross output depending on weather conditions and the economic development level of a specific country. Reliable prediction tools would have helped to avoid most of those losses in different industries.

Reliability tests of technical systems are performed in special laboratories and centers. Today, there is a great deal of experience in simulating operating conditions of materials, products, and structures in order to predict and increase their reliability. Shaping the modernday infrastructure and test facilities is an integral and necessary part of the development of this area. However, there is no legal framework for the design of test centers for technical systems. There are no principles for architectural and space-planning design of such centers as a separate design object, as well as no functional and design requirements for their architectural solutions.

\section{Materials and methods}

\subsection{The object of the study is test centers for technical systems}

The subject of the study is specific features of the functional technological design in the existing test centers for technical systems.

The objective of the study is to identify functional technological processes in the existing test centers for technical systems in order to develop their architectural and space-planning design.

The methodology of the study is based on a systems approach for complete architectural objects of various levels of the hierarchy.

\section{Results and discussion}

\subsection{Review of the international experience in reliability testing of technical systems}

The USA has a network of special centers where materials and machines (civilian and military) are tested in 14 climate zones: from the extremely hot dry climate in the Arizonian desert to the cold climate in Alaska [2]. Both field and accelerated tests are performed according to a uniform system.

The international network Atlas is the global leader in testing of materials, products, and technical systems. For over 30 years, Atlas has been conducting field tests and has 23 sites which cover all the climate zones. Q-Lab test centers have $120,000 \mathrm{~m}^{2}$ sites for outdoor testing with field and accelerated field methods in Arizona and Florida. Q-Lab indoor accelerated testing laboratory in Florida occupies an area of $900 \mathrm{~m}^{2}$ [4].

In 1940, the U.S. Air Force built the test center in Ladd Field in Fairbanks (Alaska, USA) to test the performance of aviation products under arctic conditions. However, the experience of such tests showed that weathering tests of large products and structures should be performed in a controlled environment and with highly regulated energy values. For this purpose, the first laboratory as a refrigerated airplane hangar was built in the U.S. Force military base at Eglin, and the weather tests of aircrafts started in May 1947 [5]. Today, the McKinley climatic laboratory has a working area of $5100 \mathrm{~m}^{2}$ with a height of $21 \mathrm{~m}$, which allows it to test aircrafts as large as a C-5A or 75 vehicles at the same time [6, 7].

The diverse environmental conditions in a relatively small region makes Hawaii one of the world's best natural laboratories for weathering testing. Rainfall, solar radiation, temperature, humidity, and wind vary significantly over relatively small distances. In Hawaii, 
there are humid tropical forests, including the world's wettest areas, arid and semiarid deserts, temperate and frozen alpine ecosystems. Besides, it features environmental conditions such as marine (with a varying severity of corrosion), volcanic, rural, etc. Such a unique climate and environmental diversity made it possible to create the Hawai'i Corrosion Laboratory [8] that includes a network of 10 climate zones to test technical systems. The test sites are located in agricultural, dry, industrial, marine, tropical forest, and volcanic environments.

The Qionghai test station is located in east Hainan (China) with the humid tropical climate. The total area of the station is $48000 \mathrm{~m}^{2}$, and the exposure area is up to $20,000 \mathrm{~m}^{2}$ [9]. The atmospheric corrosion station Wanning is located in Hainan Province with the coast humid tropical climate, and it is the main facility in China for testing of materials and products in the marine environment.

The Austrian company Rail Tec Arsenal (RTA) is one of the largest organizations in Europe, which conducts weathering and aerodynamic tests of transport systems. It owns two climatic wind tunnels: Large Climatic Wind Tunnel (LWT) with a length of $100 \mathrm{~m}$ and Small Climatic Wind Tunnel (SWT) with a length of about $34 \mathrm{~m}$. These dimensions make it possible to test a train with 4-5 carriages. The company also conducts weathering tests for aviation products, trams and subway cars, trucks and buses, vehicles, ski lifts, etc. [10, 11].

There are only two internationally standardized test centers in Russia. The first one is located in Moscow, with the site on the roof of one of the buildings of the All-Russian Institute of Aviation Materials (VIAM) where tests are performed in the conditions of the industrial city. The second one is located in Gelendzhik, by the seashore (VAIM's Akimov Gelendzhik Climatic Testing Center) [2]. It is situated on the west shore of the Gelendzhik Bay and occupies a total area of $12800 \mathrm{~m}^{2}$. It includes the atmospheric testing ground and the laboratory research building [12].

The atmospheric testing ground includes the following sites:

- outdoor atmospheric site equipped with 34 test benches which can accommodate up to 8000 specimens;

- atmospheric site under shed with an area of $288 \mathrm{~m}^{2}$ which includes test benches to expose up to 1000 specimens and equipment to study simultaneous action of climatic factors and loads, simultaneous exposure of specimens and whole structures to seawater;

- load floor with an area of $200 \mathrm{~m}^{2}$, which is equipped with test benches to test large structures and with special equipment to test individual assemblies and components of structures when subjected to a combination of climatic factors and static or dynamic loads.

The load floor is equipped with a unique bench to test large structures. It has been designed by Walter+Bai AG (Switzerland) according to VIAM's requirements specification. This bench makes it possible to conduct tests in the marine environment with simultaneous cyclic loading up to $250 \mathrm{kN}$.

Today, work is under way to combine the centers into one network in order to create a common information field. Such network requires that technical systems are tested according to common standard procedures [13-17 and others], which requires the use of standard equipment, standard infrastructure, as well as a uniform test process. The key is to create a legal framework for designing test centers of technical systems, develop principles for architectural and space-planning design of such centers as a separate design object, as well as functional and design requirements for their architectural solutions.

\subsection{Test procedures for technical systems}

Today, as shown in [18], test procedures for technical systems are primarily based on two methods:

- the first method is a field exposure in special outdoor sites of the stations located in representative areas of corresponding climate zones [13, 14]; 
- the second method is accelerated testing with simulating the operation of technical systems in a laboratory environment using accelerated modes [19-21].

Each method has its advantages and disadvantages. The first method takes into consideration all the factors that affect products during their operation, however, the test duration is comparable to a life of these products. Besides, it can be difficult to compare investigation results due to variations of climatic variables every year. The second method makes it possible to reduce test duration by ten folds and perform investigations under strictly regulated conditions. The main disadvantage of this method includes problems resulted from a possible change in ageing and failure mechanism of materials when subjected to accelerated testing, which often leads to prediction errors. For these reasons, the mixed method is used. It combines field and accelerated tests when specimens are first exposed to field conditions and, as a result, incubation processes start in materials in operating conditions, and then acceleration is performed in a laboratory environment.

There are also methods of accelerated testing in field conditions using special equipment:

- outdoor atmospheric testing grounds equipped with test benches to test large structures and with special equipment to test individual assemblies and components of structures when subjected to climatic factors and static or dynamic loads simultaneously [12];

- standard ASTM D 4141, Method A includes material testing in the so-called «black box». This bench is used to simulate operating conditions of automotive parts with a higher intensity of sunlight and weather factors [15];

- the ASTM standard regulates accelerated field tests on benches with an automatically moving frame that continuously and automatically changes the position of the plane of the frame front and test specimens on it and continuously positions it perpendicular to the sunlight direction [17].

It is obvious that it is necessary to use a systems approach for independent and combined application of the above test procedures, as well as to correct them on a case-by-case basis in order to ensure correct simulation of operating conditions of technical systems for prediction of their reliability and durability. For these reasons, as shown in [18], development of test methods should include two main stages:

- developing an operation chart and finding energy values of the factors responsible for ageing and failure of a specific product under specified conditions;

- transforming energy values of operational factors to bench test conditions.

The following conditions are required to support the existing test procedures for technical systems in the centers:

- equipping the centers with a system of hardware necessary for specified test procedures;

- developing logistics for schemes of arrangement and interaction of laboratory and test sites in the centers;

- developing architectural and space-planning design for the centers;

- developing functional and design requirements for architectural solutions of the centers.

\subsection{Structural elements of test centers for technical systems}

The analysis of the existing test centers for technical systems and test procedures made it possible to identify the main infrastructure elements, as well as their equipment, which helped to lay down the principles of architectural and space-planning design of such centers as a separate design object after development of the logistics for the schemes of arrangement and interaction of laboratory and test sites.

The main infrastructure elements and equipment were updated according to the Russian and foreign standards about field and accelerated laboratory tests of technical systems (GOST 9.906, GOST 9.708, GOST 9.053, ASTM G7/G7M, ASTM D 1435, ASTM D4141/ D4141M, ASTM G24 - 13, SAE J 2230, ASTM C1257, ASTM D5208, ASTM D5894, etc.). 
Testing and research were classified according to GOST 16504.

Thus, architectural and space-planning, as well as technical solutions should ensure compliance with the following requirements in order to implement a functional profile of test centers for technical systems:

- conditions for testing when subjected to a combination of climatic and biological factors, as well as factors of special environments, with performing field (in outdoor and indoor atmospheric testing grounds), laboratory accelerated tests and implementing field simulation test methods when subjected to operational factors or their equivalents;

- conditions for testing on special large indoor testing grounds including simulation of endemic factors;

- conditions for accommodating laboratory equipment for testing and research before and after exposure of technical systems.

It is recommended to situate outdoor atmospheric testing grounds at the representative and/or extreme sites of climate regions according to GOST 16350 and GOST 24482.

The main infrastructure elements of test centers for technical systems are as follows:

- a building with scientific laboratories;

- an atmospheric testing ground on the outdoor site;

- an indoor mycological testing ground;

- a building with a laboratory for testing large technical systems;

- an administration building;

- auxiliary facilities and transportation systems to ensure the vital activity of a center.

\section{Conclusion}

The review of the international experience in design and operation of the laboratories and test centers for reliability testing of materials, products, and structures of various purposes made it possible to identify functional and technological prerequisites for architectural and space-planning design of test centers for technical systems. Identified functional technological prerequisites are used to define principles for architectural and space-planning design of buildings and outdoor testing grounds of test centers for technical systems.

1. Substantiating a functional profile and make general layouts of laboratory and test sites in test centers.

2. Developing a scheme of laboratory and test sites in test centers.

3. Developing functional and design requirements for architectural solutions of test centers.

4. Selecting basic engineering solutions to design laboratory and test sites in test centers.

5. Creating the most efficient functional technological relationships.

\section{References}

1. L.N. Aleksandrovskaya, V.I. Kruglov, A.G. Kuznetsov et al. Theory of testing and experiment processing of complex technical systems. ISBN 5-94010-145-3. - M.: Logos Publ., 736 (2003).

2. E.N. Kablov. Corrosion and life, Science and life 11, 16-21 (2012).

3. K.I. Eremin, E.L. Alekseeva, S.A. Matveyushkin, Yu.V. Berezkina. Assessment, monitoring, electronic certification of building and structures, Mezhdurechye, 26-29 (2009).

4. URL: www.atlas-mts.com. 
5. McKinley Climatic Laboratory, Eglin Air Force Base, Florida (PDF). McKinley Climatic Laboratory brochure. ASME. URL: http://files.asme.org/ASMEORG/Communities/ History/Landmarks/5590.pdf. Retrieved 2009-01-06.

6. McKinley Climatic Laboratory. Aviation: From Sand Dunes to Sonic Booms. US National Park Service. URL: http://www.nps.gov/history/nr/travel/aviation/mck.htm. Retrieved 2009-01-06.

7. URL: https://www.navalgazing.net/McKinley-Climatic-Laboratory.

8. URL: http://www.hawaiicorrosionlab.org/.

9. Introduction to atmospheric corrosion research in China, Science and Technology of Advanced Materials 8 (7), 559-565 (2007). DOI: 10.1016/j.stam.2007.08.010.

10. URL: https://www.rta.eu/en/about-us.

11. URL: http://docplayer.ru/38998481-Rail-tec-arsenal-klimatichesko-aerodinamicheskiykanal-v-vene.html.

12. URL: http://gcki.viam.ru.

13. ASTM G7/G7M. Standard Practice for Atmospheric Environmental Exposure Testing of Nonmetallic Materials.

14. ASTM D 1435. Standard Practice for Outdoor Weathering of Plastics.

15. ASTM D4141/D4141M - 14. Standard Practice for Conducting Black Box and Solar Concentrating Exposures of Coatings.

16. ASTM G24-13. Standard Practice for Conducting Exposures to Daylight Filtered Through Glass.

17. SAE J 2230. Accelerated Exposure of Automotive Interior Trim Material Using outdoor Under-Glass Controlled Sun-Tracking Temperature and humidity apparatus.

18. A.M. Suleymanov. Actual problems in durability prediction polymeric building materials, J. Stroitelnie materiali 5, 10-13 (2015).

19. AATCC TM186 Weather Resistance: UV Light and Moisture Exposure.

20. ASTM C1442 Practice for Conducting Tests on Sealants Using Artificial Weathering Apparatus.

21. ASTM D5208 Standard Practice for Fluorescent Ultraviolet (UV) Exposure of Photodegradable Plastics. 